\title{
Elaboração de Casos PARA O ENSINO DE ADMINISTRAÇÃO
}

\author{
Antonio Carlos Gil. \\ Doutor em Ciências Sociais pela Fundação Escola de Sociologia e Politica \\ de São Paulo e em Saúde Pública pela Universidade de São Paulo. \\ Professor Universitário. Coordenador do Programa de Mestrado em \\ Administração da Universidade Municipal de São Caetano do Sul. \\ Instituição: \\ Universidade Municipal de São Caetano do Sul (SP) \\ E-mail:acgi@@uol.com.br
}

\section{RESUMO}

Este trabalho tem como objetivo fornecer elementos teóricos e práticos para subsidiar a elaboração de casos para serem utilizados no ensino de Administração. Procede-se inicialmente à análise das vantagens e limitações do método de caso, para, em seguida, indicar as circunstâncias em que se recomenda a utilização dessa estratégia de ensino. Procede-se ainda, à apresentação das bases filosóficas e psicológicas que conferem fundamento teórico ao método de casos. A maior parte do texto é dedicada, no entanto, ao esclarecimento dos procedimentos que são adotados na elaboração de casos, envolvendo: identificação do problema, definição de objetivos, localização do caso, coleta das informações requeridas, análise da dificuldade do caso, teste e redação final. Ênfase especial é conferida à redação do caso, com a apresentação de normas e sugestões relacionadas à estruturação do texto, ao estilo de redação e à forma de apresentação.

Palavras-chave: Método de casos, Administração, ensino, aprendizagem, redação do caso.
This paper offers theoretical and practical elements for cases elaboration in management courses. Initially, it presents advantages and limitations of the case method. Then, it indicates when cases are useful. It also discusses the philosophical and psychological fundaments of the case method. Most of the text, however, is dedicated to explaining the conduct in the preparation of the cases, involving: problem identification, definition of objectives, case localization, data collection, analysis of its difficulty, testing and final writing. The paper gives special attention to the process of writing cases, with the presentation of norms and suggestions of text structure, writing style and presentation form.

Key words: Case method, Management, teaching, learning, case writing. 


\section{INTRODUÇÃO}

O método de casos vem se tornando estratégia de ensino cada vez mais popular nos cursos de Administração. Os professores utilizam-nos para ensinar a complexidade dos mais diversos problemas na gestão das organizações. O que é plenamente justificado, pois o estudo de casos proporciona ao aluno muito mais do que a memorização ou a compreensão dos fatos administrativos, mas permite que este se coloque no papel de administrador numa autêntica situação de gestão. Com efeito, os casos possibilitam uma aproximação da realidade muito maior do que as tradicionais aulas expositivas e leituras. Sem contar que sua eficácia tem sido verificada em pesquisas no campo da Psicologia da Aprendizagem.

O método de casos no estudo de Administração vem se tornando tão significativo que algumas universidades mantêm laboratórios e bibliotecas para elaborar e disponibilizar casos, como a Universidade de São Paulo, com sua Biblioteca de Estudos de Caso em Administração Geral e a Universidade Federal da Paraíba, com o seu Laboratório de Estudos e Casos em Administração. A Associação Nacional de Pós-graduação em Administração, por sua vez, estabelece que trabalhos a serem apresentados em seus encontros anuais podem ser submetidos também na forma de Casos em Administração Brasileira, com o objetivo de procurar a convergência entre a academia e a prática empresarial.

O uso que é feito dos casos nas escolas de Administração, no entanto, nem sempre conduz aos objetivos pretendidos. Muitos professores, embora detentores de experiência no ensino de Administração, tendem a rejeitá-los em virtude de sua preferência por estratégias mais clássicas, como a da exposição. Muitos alunos, por sua vez, tendem a encarar o método de casos como um processo cansativo, que deixa muito a desejar, deixando clara sua preferência pelos métodos tradicionais de ensino.

O que ocorre é que, apesar da reconhecida eficácia do método de casos no ensino de Administração, bem como no de muitas outras áreas, seu uso nem sempre tem ocorrido de forma adequada. Muitos professores, sem maior preparo pedagógico e sem conhecimentos significativos dos fundamentos teóricos dessa estratégia, elaboram seus próprios casos e aplicamnos a alunos em circunstâncias inapropriadas. O que contribui para que a aplicação dos casos seja feita de forma amadora, levando professores e alunos a duvidar de sua eficácia.

O que se pretende neste trabalho é apresentar o método de casos como estratégia das mais eficazes para o ensino de Administração. Assim, serão consideradas as bases filosóficas e psicológicas em que se fundamentam, as vantagens e limitações desse método, as circunstâncias em que seu uso é adequado e os cuidados a serem tomados em sua elaboração.

\section{CONCEITUAÇÃO}

Casos são relatos sobre situações por meio dos quais indivíduos ou grupos podem tomar decisões ou solucionar problemas. Os casos em Administração são, portanto, descri- ções de situações administrativas reais que envolvem algum tipo de problema para o qual se requer uma solução (ERSKINE, LEENDERS, MAUFFETTE-LEENDERS, 1998). Dessa forma, os casos podem ser entendidos como uma estratégia de ensino meio dos quais uma parte da realidade é trazida para a sala de aula para ser trabalhada pelos alunos e pelo professor.

Os casos se distinguem outras estratégias de ensino porque são descrições de situações reais vivenciadas por administradores em organizações e não construções elaboradas pelos professores. Mas, apesar de terem sido retirados de situações reais para os quais houve uma decisão conhecida, esta não é apresentada, restando aos alunos a tarefa de determinar qual a solução mais adequada. São utilizados apenas como catalisadores da discussão. O que se espera com o uso dos casos é que o estudante se coloque no lugar da pessoa a quem cabe tomar a decisão ou resolver o problema. Dessa forma o estudante tem uma oportunidade para desenvolver habilidades administrativas num ambiente de laboratório.

\section{EVOLUÇÃO DO MÉTODO DE CASO}

O método de casos constitui nos dias de hoje importante estratégia para favorecer a aprendizagem nos programas de formação, treinamento e desenvolvimento profissional. Seu uso, no entanto, é muito antigo. Na Grécia Antiga, Platão valia-se de casos reais para injetar entusiasmo nas discussões filosóficas. Também na China, há mais de 2.500 anos, os filósofos Lao-Tsé e Confúcio costumavam apresentar dilemas a seus discípulos, que os discutiam visando encontrar soluções. O uso moderno desse método, no entanto, iniciou-se nos cursos de Direito, com Christopher Langdell que o introduziu na Universidade de Harvard, em 1880, com a alegação de que os alunos poderiam aprender melhor estudando as decisões dos tribunais do que lendo textos jurídicos. Logo, o método de caso passou a ser aceito em muitos outros cursos de Direito. Progressivamente, passou a ser adotado em outros cursos, como o de Medicina, e tornou-se a estratégia fundamental de ensino da Harvard Business School por volta de 1910 (McNAIR, 1954).

Nos dias atuais, o método de casos é reconhecido como um dos mais adequados para o ensino superior e seu uso vem se tornando cada vez mais freqüente na maioria dos cursos universitários (GIL, 1997). Nos cursos a distância, constitui uma das mais eficazes estratégias. É, porém, nos cursos de Administração, que seu uso encontra-se mais disseminado. O que se justifica, pois o método de casos mostra-se adequado para o ensino das mais diversas áreas da Administração, como Recursos Humanos, Marketing, Finanças e Produção. Além disso, o uso de casos em sala de aula torna-se bastante estimulante para os professores, já que lhes permite permanecerem atualizados com as situações práticas e modelos de gestão utilizados no mundo das organizações (MAXIMIANO, 2001). 


\section{FUNDAMENTOS TEÓRICOS DO MÉTODO DE CASO}

Poucas estratégias de ensino apresentam fundamentação filosófica e psicológica tão significativa como o método de casos. Por um lado, este método insere-se na perspectiva humanista de educação (GIL, 1997), que se fundamenta na crença de que os alunos não são criaturas passivas, prontas para serem modeladas pelos professores. No método de caso está implícita a rejeição da idéia de que os alunos devem primeiro aprender passivamente para depois aplicar o conhecimento. $\mathrm{Na}$ verdade, o método de casos associa diretamente o conhecimento à ação. Ele se baseia no princípio de que a educação significativa consiste na aquisição cumulativa de conhecimentos e na reorganização de experiências de aprendizagem. Um dos fundamentos do método de caso é, pois, a crença na capacidade que os alunos têm para o desenvolvimento de habilidades por meio de suas experiências pessoais. Também em apoio a esse método, costuma-se lembrar que muitos conhecimentos e julgamentos não podem ser diretamente ensinados, mas sim aprendidos por intermédio da experiência prática. Assim, o método de casos utiliza o mundo real e complexo como seu foco e os estudantes nele envolvidos são desafiados a desenvolver habilidades para lidar com problemas práticos.

A criação do método de caso deveu-se principalmente à experiência de professores norte-americanos no final do século XIX. Sua fundamentação teórica, no entanto, só começa a aparecer em meados do século XX. Uma das primeiras contribuições teóricas a esse método foi proporcionada por John Dewey (1976), o pioneiro da Escola Nova, no livro Experiência e educação, que tem como principal característica a proposta de utilização dos métodos ativos. Nessa obra, publicada originariamente em 1938, Dewey recomenda aos professores que examinem alternativas que possibilitem prover os estudantes com experiências e oportunidades para interação. Assim, o método de casos tornou-se um dos preferidos pelos educadores comprometidos com os princípios da Escola Nova.

O modelo educacional conhecido como construtivista também contribuiu para conferir fundamentação teórica a esse método. Segundo o construtivismo, o conhecimento nunca é dado como algo concluído. Ele se constrói pela interação das pessoas com o meio físico e social, com o simbolismo humano, com o mundo das relações sociais. $\mathrm{O}$ construtivismo se opõe à forma de transmissão que consiste em ensinar o que já está pronto e enfatiza a construção com base na realidade vivida por professores e alunos. Com efeito, o método de caso pode ser visto como um procedimento que favorece a construção do conhecimento, para o qual concorrem, em condição de complementaridade, por um lado, os alunos e professores e, por outro, os problemas atuais e o conhecimento já construído (BECKER, 1992).

O método de casos mostra grande coerência com a postura moderna em educação, que procura focar mais a apren- dizagem do que o ensino. O professor, ao adotar este método não se direciona pelas preocupações imanente à perspectiva clássica de ensino, que se referem principalmente ao que ensinar e ao quanto ensinar. A primeira regra no delineamento do estudo de caso é partir de onde está o estudante. O professor precisa definir quem é o estudante e quais suas necessidades. A partir deste ponto é que se constrói o conhecimento requerido.

O método de casos também apresenta vínculos com a Teoria de Campo, desenvolvida a partir dos estudos de Kurt Lewin (1973) e que deu origem às técnicas de Dinâmica de Grupo. Essa teoria, que fundamenta técnicas amplamente utilizadas em treinamento de pessoal, confere importante atenção à relação entre os indivíduos no âmbito dos grupos e admite que os grupos mobilizam poderosas forças que influenciam decisivamente os indivíduos e que podem favorecer o aprendizado. Tanto é que em muitos manuais o método de caos aparece como técnica de trabalho em grupo.

\section{VANTAGENS E LIMITAÇÕES DO MÉTODO DE CASO}

O método de caso apresenta uma série de vantagens em relação a outros métodos utilizados no ensino da Administração. Mas também apresenta uma série de limitações. $O$ que significa que seu uso deve subordinar-se a um rígido planejamento de ensino. Segue, pois, a apresentação das principais vantagens e limitações desse método de ensino.

\subsection{Vantagens}

- Possibilita o estabelecimento de vínculos entre o ambiente de ensino e o mundo real das organizações;

- Favorece o desenvolvimento de habilidades cognitivas, como análise, síntese e julgamento;

- Estimula os alunos a serem protagonistas ativos no processo de ensino;

- Conduz aos alunos à procura de mais de uma resposta correta;

- Favorece o estabelecimento de relações entre variáveis;

- Estimula a criatividade dos alunos e dos professores;

- Favorece o desenvolvimento de habilidades interpessoais, visto que de modo geral os casos são estudados em pequenos grupos, nos quais os integrantes precisam comunicar-se e influenciar as decisões de seus colegas;

- Favorece a análise de um problema segundo diferentes pontos de vista;

- Ajusta-se a diferentes níveis de complexidade do ensino;

- Pode ser utilizado tanto no ensino presencial quanto no ensino a distância, já que podem der estudados e discutidos independentemente da presença física dos professores e estudantes. 


\subsection{Limitações}

- Por se referirem a situações reais, que são fortemente afetadas por fatores econômicos, políticos e sociais, têm vida útil muito curta. Os professores que o utilizam necessitam, portanto, certificar-se de que seu prazo de validade não está vencido;

- Sua eficácia depende de elevados níveis de motivação e envolvimento por parte dos alunos;

- Sua aplicação requer bastante tempo, o que o torna inaplicável em disciplinas com carga horária reduzida;

- Devem desenvolvidos sistematicamente no âmbito de determinado curso. Quando ocorrem ocasionalmente, os alunos e também os professores tendem a se sentir desconfortáveis com esse método;

- Exigem considerável grau de controle do professor sobre a classe. Para fazer com que os alunos expressem suas idéias, o método de caso pode dar aos estudantes a impressão de que todas as idéias são igualmente boas. Torna-se necessário, então um esforço adicional para levá-los a distinguir entre boas e más idéias;

- Requer muito mais energia e tempo que as estratégias tradicionais de ensino;

- Exige muito mais preparação dos alunos do que as estratégias tradicionais, além de exigir que expressem publicamente suas idéias e submetam-nas à crítica;

- Seu sucesso depende do envolvimento dos outros professores. Quando alguns poucos professores adotam esta estratégia, sua aceitação por parte dos alunos tende a se tornar crítica.

\section{QUANDO O MÉTODO DE CASOS É APROPRIADO}

Apesar de seu evidente potencial, o método de casos não pode ser usado indiscriminadamente no estudo de Administração. Com base nos pressupostos teóricos que o fundamentam e na experiência de educadores, considera-se que o método é mais apropriado quando:

- Enfatiza-se o uso de habilidades crítico-analíticas e de solução de problemas,

- A participação ativa dos alunos é desejada;

- A capacidade de aprender a aprender deve ser estimulada:

- Há tempo suficiente para a discussão dos casos;

- Os alunos dispõem de informações suficientes para analisar o caso;

- Existem várias soluções aceitáveis para o caso;

- Os professores dispõem de prática suficiente para a sua adequada condução;

- O professor aceita desempenhar o papel de líder da discussão, e não a de um leitor de casos ou principal agente do processo deda análise;
- É possível a solução sinergística do problema pela equipe

É importante considerar que a adoção do método de casos, assim como de qualquer outro, depende da natureza dos objetivos que se deseja alcançar. Considerando a taxionomia de objetivos educacionais, definida por Bloom (1985), o método de casos constitui estratégia muito adequada para o alcance de objetivos cognitivos, mas pouco adequada quando se trata de objetivos de natureza afetiva, que se referem a sentimentos ou atitudes, ou de natureza psicomotora, que envolvem trabalho de natureza neuromuscular.

Mesmo no domínio cognitivo, convêm considerar seus diferentes níveis. O primeiro nível refere-se à aquisição de $c o-$ nhecimentos, entendida esta no sentido de recordação de determinada informação previamente aprendida. $\mathrm{O}$ método de casos não se mostra muito apropriado para o alcance de objetivos neste nível, para os quais torna-se mais adequado o uso de aulas expositivas ou de leituras. O segundo nível refere-se à compreensão, ou seja, à habilidade para aprender o significado de determinado material e reafirmá-lo sob novas formas. Também neste nível o valor do método de caso não se mostra tão evidente. O terceiro nível é o da aplicação, que se refere à habilidade para usar o material aprendido em situações concretas, envolvendo a aplicação de regras, métodos, conceitos, princípios, leis e teorias. Aqui, o método de caso torna-se um dos mais recomendados, já que o que se pretende é possibilitar a aplicação de conhecimentos teóricos num contexto real. (BLOOM, 1985).

A maior aplicabilidade do método de casos dá-se, no entanto, nos níveis mais elevados do domínio cognitivo: análise, síntese e avaliação. O nível de análise é o que implica a capacidade para decompor um todo em suas partes componentes. É neste nível que o método de casos mostra sua maior aplicabilidade, pois o que se espera com sua aplicação é a identificação das partes de uma organização, a análise das relações entre elas e o reconhecimento dos princípios organizacionais envolvidos. O nível seguinte é o da sintese, que se refere à habilidade para combinar um certo número de elementos com vistas a formar um todo coerente. Este processo pode envolver, por exemplo, a elaboração de um plano de operações ou a organização de um departamento. Também para alcançar objetivos neste nível recomenda-se o método de casos, pois ajuda a desenvolver as habilidades requeridas para estas ações, à medida que passa a exigir dos estudantes a identificação das informações relevantes, a sumarização dos conceitos fundamentais e a apresentação de sínteses significativas. O último nível, por fim, é o da avaliação, que se refere à habilidade para julgar o valor do material para um propósito definido. É justamente neste nível que o método de caso encontra maior aplicabilidade. No estudo de caso, após a análise e síntese de um caso particular, o que se requer dos estudantes é exatamente o seu engajamento na avaliação de políticas alternativas ou estratégias para serem consideradas pelos gerentes (BLOOM, 1985). 


\section{TIPOS DE CASO}

Os casos podem ser classificados de diferentes maneiras. Considerando-se os objetivos pretendidos, costuma-se classificá-los em casos-problema, que visam chegar à melhor solução com os dados disponíveis e casos-análise, que visam desenvolver a capacidade analítica dos estudantes. Mas há classificações mais rigorosas, que consideram outras dimensões, como a proposta por Harling (2004), que trata de historietas, casos para solução de problemas técnicos, casos curtos, casos longos e casos inovadores ("groundbreaking"). Para os propósitos do presente trabalho, os casos são classificados em:

- Caso-ilustração. Constitui a modalidade mais simples. Restringe-se à apresentação de uma situação verificada no contexto de uma determinada organização. De modo geral, nestes casos não se solicita do estudante a sua análise com vistas à tomada de uma decisão, pois esta já é apresentada na descrição. Esta modalidade de caso é utilizada para ilustrar situações de forma individual ou comparativa e aparece, com muita freqüência em livros didáticos de Administração, ao final de cada capítulo.

- Caso-análise. Propõe aos estudantes a análise do caso, mediante sua decomposição em partes significativas e a identificação da relação entre as variáveis. São muito utilizados em sala de aula com o objetivo de desenvolver a capacidade analítica. Sua elaboração não demanda cuidados muito maiores do que os requeridos para o caso-ilustração. Sua aplicação, no entanto, exige maior dedicação do estudante, bem como preparação do professor.

- Caso-problema. Constitui o tipo mais complexo e tem como objetivo desenvolver nos estudantes muito mais do que a capacidade analítica. Ele requer do estudante a elaboração de uma síntese com base nos dados apresentados e apresentação da melhor solução possível para o problema. Os casos-problema com mais elevado nível de estruturação são os que seguem o modelo da Universidade de Harvard. Estes casos costumam requerer do estudante mais do que a solução do problema, pois nem sempre este aparece claramente no texto. Os estudantes têm que identificá-los, apresentar possíveis soluções e ponderar as vantagens e desvantagens de cada uma delas.

\section{A ELABORAÇÃO DO CASO}

\subsection{Identificação do problema}

Todo caso se inicia com um problema ou questão a ser solucionada. Pode ser um pequeno problema de natureza tática, como, por exemplo, a cobrança de um cliente inadimplente. Mas também pode ser um problema mais amplo, como a definição de políticas da empresa. Também é possível identificar mais de um problema, já que casos complexos geralmente envolvem vários problemas simultaneamente. Os problemas podem se referir aos mais diversos domínios da organização, como os referentes à introdução de novas tecnologias, à redução de custos, a deficiências mercadológicas, à comunicação ou ao desempenho deficiente no trabalho.

Para identificar o problema, o professor deve analisar o conteúdo da disciplina que ministra ou pretende ministrar, destacando os itens que envolvem a problematização. A seguir, passa a identificar o problema ou problemas subjacentes e a delimitá-los até que assumam uma dimensão viável para estudo. É importante considerar este ponto, pois existe a tendência para identificação de problemas tão amplos, genéricos e imprecisos que se torna difícil não apenas solucioná-los, mas formulá-los adequadamente.

\subsection{Definição dos objetivos}

Após a identificação do problema, passa-se à definição dos objetivos do caso. Para isso, torna-se necessário antecipar os resultados esperados pela organização ou pelas pessoas envolvidas em relação ao problema apresentado. Como os propósitos do caso são de natureza didática, torna-se necessário definir os objetivos numa perspectiva educacional, o que significa que devem se iniciar com verbos que deixem claras as alterações pretendidas em termos de aprendizagem, como por exemplo: identificar problemas, desenvolver conceitos, adquirir habilidades no uso de técnicas, desenvolver novas técnicas, adquirir habilidades na solução de problemas etc. A formulação desses objetivos é que irá determinar a direção a ser tomada na estruturação e apresentação do caso.

\subsection{Localização do caso}

Tendo sido definidos os objetivos, a etapa seguinte consiste na localização de um ou mais casos cuja análise, discussão e solução correspondam a esses objetivos. Para localizálos, o professor poderá valer-se de entrevistas com executivos e empresários, consulta a colegas que lecionem a mesma disciplina ou disciplinas afins ou a pesquisadores, sobretudo envolvidos na elaboração de teses ou dissertações. Poderá, também consultar anais de seminários, fóruns e congressos, relatórios de empresas, trabalhos de conclusão de curso e artigos publicados em revistas especializadas.

\subsection{Coleta da informação requerida}

A elaboração dos casos requer um conjunto de informações, que podem ser obtidas de fontes de primeira mão, tais como as que são proporcionadas por executivos e empresários, e de segunda mão, tais como relatórios de consultoria, reportagens publicadas em jornais, pesquisas acadêmicas e artigos de revistas especializadas. Sempre que possível, devese utilizadas múltiplas fontes de evidência, com vistas a garantir maior fidedignidade das informações. Nesse sentido, convêm considerar que alguns dados encontram-se disponíveis dentro da organização, sob a forma escrita; alguns dos quais 
são facilmente acessíveis e outros, altamente confidenciais, são difíceis de obter. Também há dados disponíveis dentro da organização, em forma não escrita, podendo ser fáceis ou difíceis de coletar. Há dados que só podem ser obtidos fora da organização. E, por fim, há dados que não são disponíveis sob forma alguma ( MAUFFETTE-LEENDERS, ERSKINE, LEENDERS, 2000).

A entrevista tem sido considerada a mais importante fonte de dados, sobretudo quando é realizada com pessoa diretamente envolvida no caso que está sendo estudado. E para que esta seja útil, requer-se que sejam tomados muitos cuidados. Deve-se evitar, por exemplo: formular perguntas cujas respostas possam causar algum tipo de constrangimento ao respondente ou induzir respostas. Requer-se do entrevistador que tenha habilidade suficiente para identificar as causas dos problemas bem como alternativas de solução rejeitadas. O entrevistador deve ser curioso e dotar-se de palpites e intuições que possam auxiliá-lo na condução da entrevista. Também deve nortear-se pela objetividade e procurar a confirmação das informações obtidas mediante o confronto com outras fontes, se possível "não oficiais".

A entrevista dever pautar-se por princípios éticos. Assim, torna-se necessário garantir que o entrevistado tenha poder de decisão para futura liberação do caso. Este deverá ser informado que o objetivo da entrevista é subsidiar a redação de um caso para ser usado em sala de aula. Convêm, pois, logo no início, informar acerca da necessidade de liberação e da conveniência de usar um disfarce. Requer-se que os problemas sejam discutidos num clima de cordialidade e respeito e que fique claro que em nenhuma hipótese serão utilizadas informações que a empresa não deseja divulgar, mesmo que obtidas por meio de outras fontes de informação.

\subsection{Análise da dificuldade do caso}

Os casos apresentam graus diferentes de dificuldade. Essas dificuldades, por sua vez, decorrem de fatores diversos. Erzkine, Leenders e Mauffette-Leenders (1998) propõem que para a análise da dificuldade de um caso considerem-se três dimensões: analítica, conceitual e de apresentação, cada uma delas subdivididas em três níveis.

Dimensão analitica. Esta dimensão relaciona-se à determinação de qual é a tarefa do estudante em relação à decisão chave ou assunto do caso. Neste sentido, o caso pode apresentar um destes três níveis de dificuldade:

1- Aqui estão o problema que a organização enfrentou e o modo como ela o solucionou.e a solução. Você acha que a solução foi adequada?

2- Este é o problema que a organização está enfrentando. Que solução você daria para o problema? Como você o solucionaria?

3- Veja esta situação. Que problemas ela envolve? Que soluções devem ser dadas?

O primeiro nível é o mais elementar. Como a decisão já foi tomada, o estudante é solicitado apenas a proceder a uma análise crítica da decisão. O segundo nível é mais complexo, já que existe um problema ainda não solucionado, o que requer do estudante a tomada de decisões. O terceiro nível é o mais complexo, pois requer do estudante a identificação do problema e também a sua solução, o que o coloca numa posição de especialista em planejamento.

\section{Dimensão conceitual.}

Esta dimensão refere-se à complexidade dos conceitos cujo uso é requerido para a solução do caso. Embora não seja fácil a tarefa de identificação da dificuldade conceitual, esta dimensão também pode ser apresentada em três níveis.

1- O caso apresenta um único conceito, claro e preciso, que pode ser compreendido pelo estudante sem maiores dificuldades;

2- Vários conceitos são combinados no caso, requerendo análise mais detida e discussão em classe.

3- O caso envolve uma combinação complexa de conceitos, requerendo ativa participação do professor com vistas à sua clarificação.

Esta dimensão está diretamente relacionada aos conceitos, teorias ou técnicas que podem ser úteis no entendimento ou na solução da situação descrita no caso. Estas podem ser localizadas em bibliografia específica ou aparecer no corpo do próprio texto, mas também podem ter sido expostas antes da apresentação do caso.

Dimensão de apresentação.

Esta dimensão refere-se à quantidade de informação que é dada no caso e como esta é apresentada. . Nela, o estudante se depara com a questão da importância e relevância da informação para o caso. Também apresenta três níveis:

1- O caso é curto, bem organizado, quase todas as informações são relevantes, contêm poucas informações estranhas e é apresentado de forma clara e direta;

2- O caso é mais longo, envolve uma quantidade maior de informações, mas que ainda são apresentadas de forma clara e direta;

3- Há uma quantidade bem maior de informações, não muito organizadas, algumas informações estranhas e geralmente é apresentado em formatos múltiplos, utilizando vídeo, por exemplo.

Estas três dimensões formam o que Erzkine, Leenders e Mauffette-Leenders (1998) denominam cubo de dificuldade do caso. As dimensões do caso são indicadas pelos eixos do cubo, nos quais indica-se o grau de dificuldade de caso. Dessa forma, elabora-se uma figura com vinte e sete cubos (Figura 1). O grau de dificuldade mais baixo corresponde ao cubo 1-1-1 e mais alto ao cubo 3.3.3. Assim, o cubo 1.1.1 corresponde a um caso muito simples, com fácil identificação do problema (dimensão analítica), com conceitos facilmente compreendidos (dimensão conceitual) e com pequena quantidade de informações (dimensão de apresentação). 
Já o cubo 3.3.3 corresponde a um caso cujo problema não está suficientemente esclarecido, envolve múltiplos e complexos conceitos e com pouca clareza na apresentação. Os autores propõem uma classificação dos casos com base na soma aritmética das dimensões, o que daria: de 1 a 2 = fácil; de 3 a $5=$ médio e de 7 a $9=$ difícil . devem ser especialistas no assunto a que se refere o caso. As mais adequadas são as que exercem funções docentes em faculdades, visto serem capazes não apenas de analisar o conteúdo do caso, mas a sua forma, pois sua finalidade é didática.

Estes analistas são solicitados a realizar mais do que uma simples revisão do caso, mas sim sua análise crítica e julgamento. Essa tarefa pode ser facilitada com a apresentação de perguntas como as apresentadas pelo Cascade Center for Public Service (1999):

- O caso é interessante e desafiador? Por que não? Que partes do caso se mostraram desinteressantes?

- Os tópicos e problemas são identificados adequadamente?

- A cronologia e organização do caso são claras?

- As informações são suficientes para sua solução?

- A pessoa a quem cabe tomar a decisão é facilmente identificada? Qual o seu papel?

- Você consegue se ver na posição do tomador de decisão?

- Que solução você daria ao problema? Você acha que podem existir diferentes opiniões e respostas ao problema?

- Podem ser identificadas diferentes alternativas para a tomada de decisões com base nas informações apresentadas?

Figura 1 Cubo da dificuldade do caso

Legenda: Dimensões: X-Analítica, Y- Conceitual, Z- De apresentação Fonte: ERZKINE et al. Teaching With Cases. Londres: School of Business Administration, The University of Western Ontario, 1998.

\subsection{Preparação da primeira versão do caso}

Antes de redigir definitivamente o caso, o autor precisa preparar um esboço preliminar do caso. Isto requer uma visão clara tanto do problema a ser solucionado quanto da organização e de seus agentes. Requer também decisão acerca da quantidade de material a ser apresentado e da seqüência dos itens. Para isso é necessário dispor de todo o material coletado, inclusive das falas dos entrevistados. De posse te todos esses dados, o autor procede à elaboração de uma primeira versão do caso. Os cuidados a serem tomados, no entanto, são os mesmos da versão final, já que esta só não é a definitiva porque o caso inda não foi testado.

\subsection{Teste do caso}

Após certificar-se de a que o caso está suficientemente claro, este necessita ser submetido a teste, para verificação de sua validade, ou seja, da capacidade que este tem para medir o que realmente pretende medir. A maneira mais prática de testar a validade de um caso consiste em submetê-lo à análise outras pessoas, pois quem escreve o caso tende a apresentar certa dificuldade para analisá-lo criticamente. Essas pessoas

\subsection{Redação do caso}

Tão logo o caso tenha sido testado e reconhecido como válido, passa-se à sua redação definitiva. Esta etapa nem sempre tem recebido a atenção necessária dos professores que elaboram casos. Mas é de fundamental importância para garantir que o método de casos torne-se eficaz para garantir a aprendizagem dos estudantes. Requer-se nesta etapa de redação o mesmo rigor técnico que caracteriza as etapas anteriores (BARRAS, 1986). Assim, com base em trabalhos de pesquisa e na recomendação de especialistas ( MAUFFETTELEENDERS et al., 2001; LEENDERS et. al., 2001 , NAUMES, NAUMES, 1999; WASSERMAN, 1994; CHRISTENSEN, HANSEN, 1987) apresentam-se cuidados a serem tomados nesta etapa em relação ao conteúdo do caso, ao estilo de redação, à apresentação do texto e à elaboração das notas de ensino.

\subsubsection{Conteúdo do caso}

Ao se iniciar a redação do caso, várias indagações costumam surgir: O que um caso deve conter? Quantas informa- 
ções devem ser incluídas? O que deve ser excluído? Em que estilo deve ser redigido? $\mathrm{O}$ nome da organização pode ser apresentado? Qual a seqüência a ser adotada? Qual deve ser a extensão do caso?

Não há respostas definitivas para estas questões. Tanto é que os casos variam muito segundo sua forma de apresentação. Alguns são apresentados de maneira breve; outros ao longo de dezenas de páginas. Alguns são apresentados sob a forma de histórias e outros sob a forma de relatórios administrativos, muitas vezes acompanhados de tabelas, gráficos, fotos, fitas de vídeo e outros materiais.

A redação dos casos depende de muitos fatores, tais como: a natureza e complexidade do caso, os objetivos pretendidos pelo autor, as informações disponíveis e o público a quem se destinam. Assim, ao redigir o caso, o autor necessita ter muita clareza acerca da influência desses fatores e ser o mais seletivo possível, pois não há como incluir todos os dados.

Como não existe uma única maneira de redigir um caso, recomenda-se que neste processo procure-se responder aos seguintes conjuntos de perguntas:

Organização

Qual o nome da organização (real ou fictício)? Há quanto tempo existe? Qual o ramo de atividade? Houve alterações significativas no negócio da organização ao longo de sua história? Quais as suas dimensões? Quais os seus produtos? Quem são os seus principais fornecedores? Quem são os seus clientes? Quem são seus concorrentes? A empresa tem uma missão definida? Qual a natureza da organização (empresa nacional, transnacional, sociedade anônima, familiar)? Como está estruturada a organização? Qual o processo normal de tomada de decisões? Qual a sua situação financeira?

Pessoas:

Localização das pessoas na organização em cuja posição o aluno deverá se colocar (nome; cargo; idade; tempo de companhia e etc.)

Local e época

Qual o cenário em que se desenvolveu o caso? Em que período ocorreu?

Descrição do caso

Qual a situação específica que constitui o foco deste caso? Quais as suas causas? Quais as suas implicações? Qual o papel da administração, dos funcionários, dos clientes e dos fornecedores no caso?

Resultados esperados

Que decisões podem ser tomadas? Quais as possíveis conseqüências de cada uma delas?

\subsubsection{Estilo}

A redação de um caso requer cuidados especiais com relação ao seu estilo. Ressalte-se que o estilo a ser adotado é o técnico. A redação, no entanto, deve ser agradável, já que serve a uma finalidade didática. Há casos que são relevantes e elaborados com dados suficientes para sua análise. Mas nem sempre seu estilo é adequado a ponto de permitir sua utilização em sala de aula. Costuma-se lembrar que a redação de um caso deve ser pautada por critérios semelhantes aos adotados na redação de um artigo para periódico científico. Seguem, portanto, algumas dicas importantes a respeito do estilo a ser adotado na redação do texto:

- Convêm que o texto seja iniciado com um parágrafo que deixe clara a situação básica em torno da qual o caso se desenrola. Este parágrafo inicial deve ser breve, mas suficiente para identificar a organização, seus atores e os itens relevantes para colocação do problema;

- O texto deve ser elaborado com clareza e precisão. As idéias devem ser apresentadas sem ambigüidade, para não conduzir a interpretações diversas. Deve-se utilizar vocabulário adequado, sem verbosidade, sem expressões de duplo sentido e evitar palavras supérfluas e repetições;

- O caso deve ser escrito usando uma estrutura que promova um fluxo fácil de pensamento para melhor entendimento pelo estudante;

- Deve-se evitar o uso de adjetivos que não indiquem claramente a proporção dos objetos, tais como pequeno, médio e grande, bem como expressões do tipo quase todos e uma boa parte. Também devem ser evitados advérbios que não explicitem exatamente o tempo, o modo e o lugar, como recentemente, antigamente, algures e alhures. Os melhores termos são os passíveis de quantificação;

- O texto deve ser conciso, ou seja, deve expressar as idéias com poucas palavras. Convêm que cada período envolva no máximo duas ou três linhas, pois períodos longos dificultam a compreensão e tornam pesada a leitura;

- O caso deve ser escrito preferencialmente no passado;

- O texto deve ser elaborado de maneira impessoal, evitando a expressão de opiniões e julgamentos pessoais, que podem influenciar a decisão dos leitores. Quando períodos longos forem inevitáveis, convêm colocar na primeira metade as palavras essenciais: o sujeito, o verbo e o adjetivo principal. Isto porque as palavras da primeira parte da mensagem são mais facilmente memorizáveis;

- Deve-se evitar a ironia e o humor, pois o leitor poderá ser induzido a pensar em falta de seriedade se o caso parecer comédia;

- Deve-se utilizar linguagem simples e evitar o uso de palavras desnecessárias. $\mathrm{O}$ uso de sinônimos pelo simples prazer da variedade também deve ser evitado. Cabe lembrar que a finalidade da redação é a de expressar, não a de impressionar;

- Embora não seja um texto literário, convém que seja elaborado de forma a provocar no leitor um certo "interesse dramático";

- Atenção especial deve ser conferida ao último parágrafo. Este deve se associar diretamente ao primeiro parágrafo do texto, que apresenta o problema de forma sintética. Ele deve esclarecer a decisão que precisa ser tomada, de maneira coerente com o início. 


\subsubsection{Apresentação do texto}

- O texto deve ser subdividido em seções e parágrafos, pois estes recursos lhe conferem suporte e favorecem a identificação de suas partes;

- Gráficos, tabelas, organogramas e outros tipos de ilustração são muito úteis porque simplificam a informação, favorecem a identificação das relações entre os vários elementos do texto ajudam na redução do tempo de leitura e análise;

- A linguagem e a terminologia usada pelos entrevistados deve ser mantida. Se alguns termos não forem muito usuais, convêm incluir um glossário;

\subsubsection{Material de apoio}

O texto pode requerer materiais de apoio, tais como transparências e fitas de vídeo.

\subsubsection{Elaboração das notas de ensino}

As notas de ensino têm como finalidade fornecer esclarecimentos ao professor que irá utilizar o caso. Elas são importantes porque auxiliam na verificação da adequação do caso e na definição de estratégias para o seu desenvolvimento. Também servem para proporcionar ao professor informações adicionais sobre o caso, o que contribui para que o professor tenha maior segurança na condução das discussões. Cabe lembrar que a segurança do professor em relação ao caso é condição fundamental para o sucesso da estratégia. Sem esta segurança, o professor não conseguirá envolver a classe na solução dos problemas propostos.

A forma destas notas varia muito, mas geralmente incluem:

- Objetivos de ensino que podem ser alcançados mediante o uso do caso;

- Problema ou situação-problema;

- Indicação dos cursos, disciplinas ou módulos de ensino em que o caso pode ser usado;

- Nível de dificuldade do caso;

- População-alvo;

- Conhecimentos prévios requeridos para a análise e solução do caso;

- Recursos didáticos requeridos para o desenvolvimento do caso;

- Informações e leituras que podem facilitar o aprendizado e a utilização do caso;

- Informações complementares sobre a organização e a situação;

- Experiências passadas relacionadas ao uso do caso;

- Informações acerca do que realmente ocorreu na organização após a ocorrência do caso;

- Questões desencadeadoras;

- Estratégia de ensino mais adequada para o envolvimento da classe (discussão com a classe toda, discussão em pequenos grupos, dramatização);

- Tarefas propostas aos alunos.

\subsection{Lista de verificação}

Nem sempre o redator de um caso fica satisfeito com seu texto. Tanto que é comum após uma primeira aplicação, o autor proceder a alterações na redação de seu texto. Por isso recomenda-se que este seja submetido a uma cuidadosa revisão. Assim, segue-se uma lista com os principais itens a serem considerados numa revisão:

- O caso possibilita alcançar os objetivos?

- Os objetivos estão ajustados ao problema?

- O caso está suficientemente completo e focalizado?

- O caso mostra-se realista?

- Todos os constituintes de uma narrativa estão incluídos no caso, como: estilo de apresentação, descrições contextuais da situação e perfis dos agentes centrais, seqüência de eventos e enredo interessante?

- Os eventos aparecem numa ordem lógica?

- Os eventos estão conectados com fórmulas de transição?

- O conteúdo do caso é acurado, relevante e apropriado?

- Este caso contém todo o material de que o leitor necessita para sua análise?

- Alguma parte pode ser retirada para tornar ocaso mais conciso sem, no entanto, dificultar o seu entendimento?

- A apresentação do caso está suficientemente clara?

- As informações oferecidas são coerentes entre si?

- O estilo de redação é adequado?

Pode ocorrer que formalmente o caso se apresente de forma satisfatória, mas apresente pontos falhos. Gentile (1990) identifica uma série de armadilhas que costumam ocorrer ao longo do desenvolvimento dos casos, às quais convêm estar atento:

- O caso sem decisão ou foco claro;

- O caso com muitos detalhes;

- O caso sem estrutura;

- O caso teórico;

- O caso sem contexto;

- O caso sem atores;

- O caso sem controvérsia;

- O caso sem drama;

- O caso em forma de piada

Volpe (2002), por sua vez, faz uma série de considerações que também podem ser úteis na revisão do caso:

- Um bom caso deve ter utilidade pedagógica, o que significa que a primeira pergunta a ser feita é a que função de ensino ele serve;

- O caso deve provocar controvérsia, pois esta é que promove o engajamento dos estudantes e os força a analisar e a defender suas posições;

- O caso é mais útil quando provoca o estudante no sentido de tomar uma decisão.

- Uma importante medida da utilidade do caso é sua capacidade de generalização;

- A brevidade é uma qualidade desejável, pois casos muito longos e que contêm muitos fatos tendem a conduzir a discussão para particularidades; 
- Um bom caso deve conter informações quantitativas apresentadas numa variedade de formas, incluindo tabelas e gráficos;

- E importante garantir que o caso não requeira do estudante grandes conhecimentos históricos ou institucionais.

\section{CONCLUSÕES}

O método de casos constitui importante estratégia para o ensino da Administração. Favorece o alcance de objetivos instrucionais nos mais diversos níveis. Para o alcance de objetivos referentes a julgamento, que constitui o mais elevado nível no domínio cognitivo, mostra-se mais eficiente que qualquer outro. Como, porém, a vida útil de um caso é limitada e as situações com que se deparam os professores de Administração são as mais diversas, requer-se a elaboração de muitos casos para atender à demanda dos cursos. Redigir casos não constitui tarefa das mais complexas. Quem se dispõe a fazê-lo deve, no entanto, cercar-se de uma série de cuidados para que os casos apresentem validade e seu uso conduza ao efetivo aprendizado dos estudantes. Estes cuidados referem-se principalmente à formulação dos objetivos do casso, à coleta e análise das informações e à estrutura, estilo e apresentação do caso.

\section{REFERÊNCIAS BIBLIOGRÁFICAS}

BARRASS, Robert. Os cientistas precisam escrever: guia de redaçãoPara cientistas, engenheiros e estudantes. São Paulo: TA Queiroz, 1986.

BECKER, Fernando. O que é construtivismo. Revista de Educação AEC. Brasília. V. 21, n. 83, p. 7-15, abr./jun., 1992.

BLOOM, Benjamin S. et al. Taxionomia de objetivos educacionais: domínio cognitivo. 8 ed. Porto Alegre: Globo, 1983.

CASCADE CENTER FOR PUBLIC SERVICE, Public Service Curriculum. Welcome to the Case Method. Cascade center for public service. Public Service Curriculum: Washington, 1999. Disponível em: $<$ http://istsocrates.socrates.berkeley.edu/ perlman/content/ writing/tipsonwriting. writingcases.html>. Acesso em: 23 mar. 2003.
CHRISTENSEN, C. R., A. J. HANSEN. Teaching and the Case Method: text, cases, and Readings. Boston, MA: Harvard Business School Press, 1987.

DEWEY, John. Experiência e educação. 2. ed. São Paulo: Nacional, 1976. EINSIEDEL, Albert A. Jr.Case studies:Indispensable tools for trainers. Training \& Development. Alexandria. v. 49, n. 8. ago. 1995.

ERSKINE, Jim A., M.R. LEENDERS, MIKE, R., MAUFFETTELEENDERS, Louise, A. Teaching With Cases. Londres: School of Business Administration, The University of Western Ontario, 1998.

GENTILE, Mary C. Twenty-five Questions to ask as as you begin to develop a new case study. Nota 9-391-042. Harvard Business School Publishing, 1990.

GIL, Antonio Carlos. Metodologia do ensino superior. E ed. São Paulo: Atlas, 1997.

HARLING, Kenneth. Overview of the case method. The Maple Leaf Conference. The International Review of Food and Agobusiness Management. Montreux, Suiça. jun. 2004. Disponível em: http:// info.wlu.ca/ wwwsbe/MapleLeaf/CASE_METH_Overview.html. Acesso em 2 abr. 2003.

LEIDNER, Dorothy.E. , JARVENPAA, Sirkka, L., The use of information technology to enhance management school education: a theoretical view. MIS Quarterly v. 29, n. 3, p. 265-291, set. 1995.

LEENDERS, Michiel R., MAUFETTE-LENDERS, Louise A., ERSKINE, James A. Writing cases. 4 ed. Londres: 2001.

LEWIN, Kurt,. Problemas de dinâmica de grupo. São Paulo: Cultrix, 1973.

MAUFFETTE-LEENDERS, Louise A.,., J.A. ERSKINE, Jim A., M.R. LEENDERS, Mike,

Learning with Cases. 4 ed. Londres: Ivey Publishing, 2000.

MAXIMIANO, Antonio Cesar Amaru. Método de caso no ensino da Administração. In

BOOG, Gustavo G. Manual de treinamento e desenvolvimento: um guia de operações. São Paulo: Makron/ABTD, 2001.

McNAIR Malcon.P. The case method at Harvard Business School. Nova York: McGraw-Hill, 1954.

NAUMES, William, NAUMES, Margareth. The Art and Craft of Case Writing.Thousand Oaks, CA: Sage Publications, 1999.

VOLPE, Guglielmo. Case Studies. Londres:London Metropolitan University, 2002. Disponível em http://www.economics.ltsn.ac.uk/ handbook/printable/casestudies_v5.pdf. Acesso em: 2 abr. 2003.

WASSERMAN, Selma. Introduction to Case Method Teaching: a Guide to the Galaxy. Nova York: Teachers College Press, 1994. 